\title{
Segurança e Defesa Nacionais: conceitos básicos para uma análise
}

National Security and Defense: basic concepts for an analysis

GUNTHER RUDZIT*

OTTO NOGAMI**

Rev. Bras. Polít. Int. 53 (1): 5-24 [2010]

\section{Introdução}

Desde o lançamento da primeira Política de Defesa Nacional (PDN) em 1996, no governo Fernando Henrique Cardoso, se debate sobre a abrangência da mesma. Mesmo com a publicação da sua equivalente no governo Luiz Inácio Lula da Silva, não se chegou a um consenso sobre o tema, com praticamente duas visões, a civil e a militar. Um bom exemplo da linha de pensamento militar é o texto de Darc Costa (1999). Nele, o autor apresenta uma construção teórica, argumentada em uma dita consagrada metodologia, na qual o planejamento de defesa estaria acima de qualquer outro, e o mesmo teria como órgão central o Ministério da Defesa (MD). Esta visão não é surpreendente entre os militares brasileiros, já que estes foram profundamente influenciados pelo movimento dos jovens turcos que estudaram na Alemanha entre os anos de 1910 e 1912, quando vivenciaram o país mobilizado para a primeira guerra mundial e praticamente comandado pelo coronel Erich Von Ludendorff, chefe do Estado Maior (Trevisan, 1993).

Uma excelente resposta a esta visão foi dada por João Paulo S. Alsina Jr (2003), que, na discussão sobre o lançamento da primeira PDN e da criação do Ministério da Defesa, faz uma rápida discussão teórica. O autor defende que o trabalho de Barry Buzan e seus colaboradores sobre o conceito de segurança e securitização, apesar de suas deficiências, tem a vantagem de superar as amarras impostas pela visão funcionalista da Escola Superior de Guerra sobre segurança. Tanto que Alsina Jr defende que defesa é a segurança militar externa, ou seja, uma política pública setorial. Assim, este artigo tem como propósito contribuir

\footnotetext{
* Doutor em Ciência Política pela Universidade de São Paulo - USP, professor de Relações Internacionais da Fundação Armando Alvares Penteado - FAAP (grudzit@yahoo.com).

** Doutorando em Engenharia da Produção pela Universidade de São Paulo - USP e professor do Instituto de Ensino e Pesquisa - Insper (OttoN@isp.edu.br).
} 
para este debate no Brasil, como Proença (1998) e Flores (2002), trazendo à luz da experiência anglo-saxã, a definição da estrutura hierárquica das Políticas de Segurança Nacional, Defesa e Estratégia. Tendo em vista que esta análise está baseada na discussão sobre concepções acerca dos conceitos envolvidos neste campo de atuação governamental, tais como segurança e segurança nacional, também será apresentada a controvérsia sobre este tema na literatura de Relações Internacionais. Por fim, será oferecida uma resposta à difícil equação da relação civil-militar e o papel de cada um na elaboração destas políticas.

\section{Segurança e Segurança Nacional}

A Segurança Nacional somente pode ser entendida como um problema político quando se tem uma ideia razoavelmente clara sobre a natureza de uma ameaça e as vulnerabilidades do objeto ao qual as ameaças são dirigidas. Esta distinção entre ameaças e vulnerabilidades aponta para a importante divisão dentro de uma política de segurança nacional, pois os Estados podem procurar reduzir as suas inseguranças através da diminuição de suas vulnerabilidades ou enfraquecendo as fontes de ameaças (Goldman, 1982, 64). Em outras palavras, uma política que procure definir as ameaças à segurança nacional tanto pode ter seu foco para dentro das fronteiras do país, a fim de reduzir sua vulnerabilidade por si mesma, quanto para fora do Estado, procurando enfraquecer as ameaças externas indo diretamente às suas causas, tanto por meio de negociaçóes como de ataques armados diretos. Quais são, então, as ameaças ou assuntos específicos de segurança (security issues)?

Atualmente há duas grandes correntes em estudos estratégicos que defendem perspectivas opostas quanto aos tópicos que devem ser considerados de Segurança Nacional: a tradicional (ou "estreita") e a nova (ou "abrangente"). O debate entre as duas posições cresceu pelo descontentamento com o imenso "afunilamento" que o campo de estudos estratégicos sofreu pela obsessão militar e nuclear da Guerra Fria. ${ }^{1}$ Este sentimento foi estimulado pelo aparecimento das agendas econômica e ecológica no cenário internacional durante as décadas de 1970 e $1980^{2}$, e mais tarde, pelo aumento das preocupações de identidades nacionais e

1 Ver; Herz, John H. International Politics in the Atomic Age. New York: Columbia University Press, 1959; Bull, Hedley. The Control of the Arms Race. London: Weindenfeld e Nicolson, 1961; BrodiE, Bernard. War and Politics. London: Cassell, 1973; Jervis, Robert. Perception and Misperception in International Politics. Princeton, NJ: Princeton University Press, 1976.

2 Ver: Ullman, Richard. Redefining Security. International Security, 8:1 (1983), pp. 129-153; Jahn, Egbert, Lemaitre, Pierre e Waever, Ole. Concepts of Security: Problems of Research on Non-Military Aspects. Copenhagen Papers, no.1. Copenhagen: Center for Peace and Conflict Research, 1987; NYE, Joseph S., e LYNN-JONES, Sean M. International Security Studies. International Security, 12:4 (1988) pp. 5-27; Brown, Neville. Climate, Ecology and International Security. Survival, 31:6 (1989) pp. 519-32; NYE, Joseph S. The Contribution of Strategic Studies: Future Challenges. Adelphi Paper no. 235. London: International 
crimes transnacionais na década de $1990 .{ }^{3}$ Contudo, esse movimento produziu uma "contra-reação", ou seja, um estreitamento dos estudos estratégicos centrados em torno dos temas de ameaças e uso da força. $\mathrm{O}$ argumento dos que defendem isso é de que a ampliação progressiva dos assuntos tratados poria em perigo a coerência intelectual dos estudos estratégicos, pois, ao se adicionar mais tópicos, acabaria por torná-lo vazio.

A maior parte dos tradicionalistas insiste no conflito militar como o elemento chave para se entender a segurança e fizeram poucas tentativas de defender a centralidade do Estado na análise de segurança, em grande parte, pela crescente presença de atores não estatais nesta nova conjuntura. Porém, alguns - como Jahn, Lemaitre e Waever (Jahn et al, 1987) - defendem o setor político como o foco principal de análise, enquanto Mohammed Ayoob (Ayoob, 1995, 6-28) defende o Estado como tal, e diminuem a importância do aspecto do conflito militar.

Apesar de pontos de vista diferentes, ambas as correntes definem o conceito de ameaça em termos de ser externo ou vindo de fora, isto é, de fora da unidade de análise mais aceita em Relações Internacionais, ou seja, o Estado. Como Ayoob bem coloca, esta definição e o processo pelo qual se chegou a tanto podem ser entendidos pelo fato de que as duas correntes refletem a trajetória de trezentos anos de desenvolvimento histórico que pode ser traçado da Paz de Wesphalia, até o fim da Segunda Grande Guerra. A evolução do sistema de Estados europeus e sua interação com os processos de política interna de consolidação nacional levaram à legitimação do sistema e dos participantes individuais. Essas duas forças - a interação entre os Estados soberanos e a grande identificação dos indivíduos com seus respectivos Estados - reforçou uma à outra, e com tal reforço, criou-se a base para a tradição mais dominante na literatura de Relações Internacionais, na qual a segurança vira sinônimo da proteção contra ameaças externas aos interesses vitais e aos valores básicos de um Estado. Por fim, Ayoob denomina essa corrente de "Conceito Ocidental de Segurança" (Ayoob, 1995, 7).

Entretanto, ainda segundo Ayoob, essa definição de segurança não pode ser aplicada na análise da situação de diversos países no mundo, primordialmente os que já foram chamados de terceiro mundo, e hoje denominados de "Sul", em desenvolvimento ou emergentes. Na sua busca por uma definição de um conceito que melhor se aplique à realidade dos países em desenvolvimento, Mohammed Ayoob elabora a ideia de que a dimensão internacional de segurança

Institute for Strategic Studies, 1989; Crawford, Neta C. Once and Future Security Studies. Security Studies, 1:2 (1991) pp. 283-316; Haftendorn, Helga. The Security Puzzle: Theory-Building and Discipline-Building in International Relations. International Studies Quarterly, 35:1 (1990) pp. 3-17.

3 Ver: Lebow, Richard N. Interdisciplinary Research and the Future of Peace and Security Studies. Political Psychology, 9:3 (1988) pp. 507-543, 508; e GraY, Coli S. Villains, Victims and Sheriffs: Strategic Studies and Security for an Inter-War Period. Hill: University of Hull Press, 1994. 
é inseparavelmente interligada ao processo de formação do Estado (State building), sendo este o núcleo da variável que determina a problemática da segurança dos Estados em desenvolvimento (Ayoob, 1992, 63-80 e 1994, 15-28). Ou seja, a definição de segurança por ele proposta tem como característica principal ser centrada no Estado, enfatizando a conotação política do termo, e a maior empreitada na qual os países em desenvolvimento estão empenhados desde a descolonização: a formação do Estado (State building).

Isto porque, ao se tentar aplicar a definição ocidental de segurança na análise da situação de países em desenvolvimento, verificar-se-ão grandes problemas de conceituação. Como exemplo, Ayoob usa o primeiro e fundamental atributo deste conceito, a proveniência externa das ameaças, pois a sensação de insegurança que estes Estados sofrem emana largamente de dentro das suas próprias fronteiras, ao invés de serem de fora delas. Apesar de essa situação não significar a inexistência de ameaças externas, as ameaças internas têm maior visibilidade, pois são abundantes nos países em desenvolvimento, podendo-se arguir que tais conflitos frequentemente se transformam em conflitos interestatais, devido ao fator de transbordamento dos mesmos para países vizinhos com os mesmos problemas internos. Assim, as vulnerabilidades internas dos Estados em desenvolvimento são as principais causas para o elevado número de conflitos em diversas partes do globo abrangidas por esses países. Portanto, a principal causa dessa situação ocorre devido às debilidades desses Estados.

Os baixos níveis de coesão social, legitimidade tanto do Estado quanto do seu regime, são as raízes das causas da situação de insegurança em que se encontram os países em desenvolvimento. Este baixo nível está relacionado à situação em que estes países se encontram, ou seja, por estarem nos primeiros estágios do processo de formação do Estado, e pela falta de tempo que os mesmos tiveram para completar as diversas fases deste processo como ocorreu na Europa Ocidental e na América do Norte. Isto ocorre porque, segundo Keith Jaggers $(1992,29)$, conceitualmente, a formação do Estado pode ser bem definida como a habilidade do Estado em acumular poder, sendo um processo pelo qual um governo não somente cresce em produtividade econômica e coerção governamental, mas também, em poder político e institucional, tendo assim, três faces distintas: (a) poder como capacidade nacional; (b) poder como capacidade política; e (c) poder como coerência institucional.

As definições de Jaggers são semelhantes às de Esward Azar e Chung-in Moon de security software $(1988,77)$, que defendem que esse conceito é integrado por três componentes primários: legitimidade, integração e capacidade política. Portanto, pode-se dizer que o nível de segurança de um Estado está relacionado ao grau de desenvolvimento político alcançado por um Estado. Além disso, ao se tomar a definição de Charles Tilly $(1985,181)$ sobre o processo de formação 
do Estado, pode-se complementar e estender o escopo dessa definição, pois, para Tilly, o Estado é a principal fonte de violência organizada, onde os agentes do Estado caracteristicamente agem em quatro atividades distintas: fazer a guerra; formar o Estado; proteger da população; e extrair riquezas.

Tendo como base estas análises, pode-se concluir que o processo de State Building pode ser descrito como o processo pelo qual o Estado não somente cresce economicamente e mantém a coerção governamental, mas também tem poderes políticos e institucionais, resultando no controle central do seu território e população, como o monopólio legítimo sobre os meios de violência dentro das fronteiras, e a capacidade de permear significativamente a sociedade que é englobada por esse Estado.

A questão fica em como definir a segurança de um Estado. Por tudo que foi visto, pode-se dizer que o significado de segurança será tão diverso quanto as condiçõos e as situações de diferentes Estados a que este conceito é aplicado, assim como o processo de formação do Estado em países em desenvolvimento é diferente dos países desenvolvidos, os primeiros enfrentam diferentes problemas de segurança do que os outros, que são a falta de legitimidade de suas fronteiras, instituições e regimes; coesão social inadequada; e ausência de consenso da sociedade em assuntos sociais, econômicos e organização política (Ayoob, 1995, 28). Portanto, os países em desenvolvimento estarão mais sujeitos a se sentirem mais ameaçados do que os desenvolvidos.

Essa maior sensação de insegurança reforçou ainda mais a tendência de expansão do conceito de segurança no mundo pós-Guerra Fria. Autores como Caroline Thomas e Jessica Mathews propuseram a ampliação desse conceito para passar a integrar a nova realidade do mundo. Thomas afirma que a segurança não se referia somente à dimensão militar, mas a uma maior, que englobasse toda a existência do Estado, como a procura por segurança interna através da construção do Estado (nation-building), por sistemas seguros de alimentação, saúde, comércio e moeda (Thomas, 1987, 1) - uma visão diferente de formação do Estado, já que nesta percepção, são os governos que moldam a realidade por meio de suas políticas setoriais. Jessica Mathews, por exemplo, procura apontar as mudanças climáticas e a devastação ambiental como as maiores fontes de insegurança nos anos noventa, e que seriam os grandes desafios do novo milênio (Matthews, 1991, 362-380). Entretanto, a própria Mathews reconhece que o impacto da degradação ambiental em tópicos de segurança é muito difuso, sendo, portanto, problemática a tentativa de se fazer esta correlação. Isto porque o declínio ambiental pode levar ocasionalmente a conflitos diretos, especialmente quando recursos hídricos escassos têm de ser divididos. Contudo, este impacto indireto na segurança das nações é sentido somente quando os reflexos da degradação ambiental afetam o desempenho econômico, e, indiretamente, na estabilidade política (Mathews, 
1991, 366). Assim, fenômenos como pobreza e degradação ambiental deveriam ser analisados como ocorrências e variáveis que poderiam ser ligadas ao campo da segurança, mas que na realidade não são partes constantes dela.

Isto se dá porque o conceito de segurança precisa ser entendido como sendo explicitamente no sentido político. $\mathrm{O}$ conceito de segurança deve ser aplicado à segurança do Estado - em termos de território e suas instituiçóes - e à segurança daqueles que representam a territorialidade e institucionalidade dele. Ou seja, uma situação de segurança/insegurança é definida em relação às vulnerabilidades, tanto internas quanto externas, que ameacem ou tenham o potencial de derrubar ou enfraquecer as estruturas do Estado (territorial e institucional) e seu regime político (Ayoob, 1995, 9). De acordo com essa definição, quanto mais um Estado ou regime pender para o lado da invulnerabilidade no continuum vulnerabilidadeinvulnerabilidade, mais seguro ele estará. Outros tipos de vulnerabilidades, tanto econômica ou ecológica, tornam-se componentes integrais da definição de segurança somente se eles se tornarem tão críticos que passem a ter dimensões políticas e ameacem as fronteiras do Estado, suas instituiçōes, ou a sobrevivência do Sistema Político. Em outras palavras, dívida externa, devastação de florestas tropicais, ou até mesmo a fome não se tornam parte do cálculo de segurança a não ser que elas possam vir a ter resultados políticos que tanto afetem a sobrevivência das fronteiras do Estado, suas instituições ou enfraqueçam a capacidade do Estado de agir efetivamente nos campos das políticas interna ou externa.

Barry Buzan e seus colaboradores também definem segurança neste sentido (Buzan et al, 1998, 21). Para eles, segurança é sobrevivência, ou seja, somente se pode falar em segurança nacional quando um assunto é apresentado como sendo uma ameaça real a algum objeto (tradicionalmente, mas não necessariamente, $\mathrm{o}$ Estado, este incorporando o governo, território e sociedade). E utilizando-se de um conceito defendido por Waever (Waever, 1995, 17) afirmam que a especial natureza da ameaça justifica o uso de medidas extraordinárias a fim de lidar com ela. Por essa razão, a invocação da segurança nacional tem sido a chave para a legitimização do uso da força, mas geralmente ela tem servido como a forma do Estado mobilizar, ou invocar poderes especiais, a fim de lidar com uma ameaça existente.

Buzan e seus colaboradores ainda fazem uma profunda e interessante análise de como esse processo se dá, ao qual eles denominam de "securitização". Para eles, quando se invoca segurança nacional é o movimento que leva a política além das regras do jogo estabelecidas e enquadra o assunto tanto como um tipo especial de política ou acima dessa. Portanto, securitização pode ser entendida como uma versão mais extremada da politização, pois, em teoria, qualquer assunto público pode ser posicionado no espectro que varia do não-politizado (significando que o Estado não lida com ele e de nenhum modo é tido como um tópico de debate 
público e de decisões), passando por politizado (significando que o tópico é parte de uma política pública, requerendo uma decisão governamental e alocação de recursos), até a securitizado (significando que o tópico é apresentado como uma ameaça existente, requerendo medidas de emergência, o que justifica ações fora dos limites normais do processo político). Em princípio, dependendo das circunstâncias, o posicionamento de qualquer tópico está em aberto, podendo estar presente em qualquer parte do espectro, pois, como visto anteriormente, uma questão pode ser conectada com outra e se dizer que é uma questão de segurança do Estado (Buzan et al, 1998, 21). Esses teóricos ainda colocam que a ligação de politização e securitização não implica, necessariamente, em ter que passar pelo Estado, sendo possível que ambos possam ser feitos em outros fóruns, como o Congresso nacional nas democracias.

Portanto, um tópico se torna de segurança não necessariamente por causa da existência de uma ameaça real, mas porque ele é apresentado como uma ameaça. Os três autores afirmam que é importante notar que o discurso de segurança não é definido pelo uso da palavra segurança, mas sim a designação de uma ameaça existente que requer uma ação emergencial ou medidas especiais, e a aceitação disso por uma parte da população (Buzan et al, 1998, 22). A grande questão passa a ser como combater estas ameaças.

\section{Segurança Nacional e Planejamento de Defesa}

Assim, a grande questão que se segue é como se dá o arranjo nas políticas setoriais dos Estados a fim de garantir a sua segurança. Tendo em vista que, para cada governo, a percepção de ameaça é diferente, as medidas tomadas também serão diferenciadas de acordo com cada realidade. A aplicação das políticas setoriais vai depender justamente desta percepção, fazendo-se necessário que se realize uma análise do conjunto de decisões e ações adotadas por um governo objetivando preservar ou criar, tanto interna como externamente, uma ordem adequada aos seus interesses e valores mais importantes, não se podendo descartar o uso da força. Neste caso, a política de defesa é somente mais um dos instrumentos para tanto.

Consultando a literatura existente na área de defesa, pode-se constatar que os conceitos de política de defesa nacional, política de defesa, planejamento de defesa ou estratégia de defesa, são usados livremente e de forma a significarem quase a mesma coisa. Em vez de decifrar a complexidade semântica da área de segurança, Stephanie Neuman usou o modelo de teia-de-aranha (Neuman, 1984, 7), que foi adaptado na figura-1 abaixo, para melhor pensar a respeito de todos esses conceitos de forma conjunta e que resultou em uma maneira muito apropriada de demonstrar a hierarquia das esferas políticas. 
Figura $1^{4}$

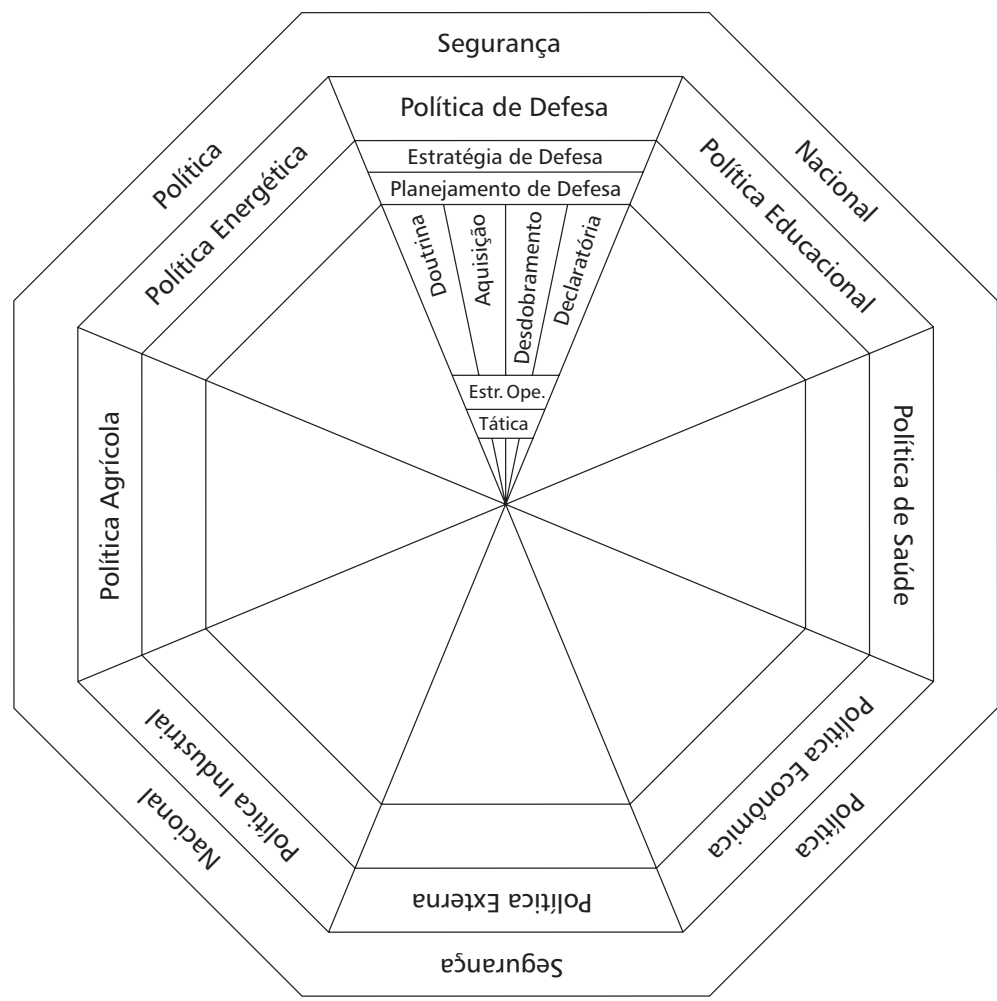

Pode-se afirmar essa hierarquização, porque, segundo esse modelo, a totalidade da figura representa a Política de Segurança Nacional. Usando o termo no seu sentido mais amplo, Newman argumenta que é nesta esfera que são articulados tanto os interesses nacionais mais amplos, quanto os objetivos do país e os meios (militares, econômicos, sociais e políticos) que serão usados a fim de promover e protegê-los. Usando o exemplo norte-americano, a autora diz que os interesses dos Estados Unidos são a preservação da integridade do Estado, o bemestar econômico dos seus cidadãos e as características do sistema socio-político americano. Por isso, a fim de proteger esses interesses, os formuladores de políticas americanos têm de resolver um grande número de temas sociais, econômicos, militares e políticos, tais como se um imposto de importação deve ser cobrado de sapatos italianos; quão longe se estendem as águas territoriais americanas sob a lei dos mares; o direito de um esportista estrangeiro permanecer no país; os termos de um acordo de limitação de armas com outros países e etc. Todos esses assuntos, assim como centenas de outros, afetam o bem-estar do povo americano, seus valores ou a soberania do Estado. Por isso, as várias políticas setoriais - saúde, impostos,

4 Figura adaptada do conceito de Stephanie Neuman, (Neuman, 1984). 
comércio exterior, agricultura, imigração, educação, defesa - representam diferentes segmentos da "teia-de-aranha", que juntos expressam os interesses políticos e de segurança nacional dos Estados Unidos. Por fim, a autora frisa que formuladores de políticas em outros países têm que enfrentar assuntos semelhantes. Apesar de não identificado por Newman, é nesse nível, da Política de Segurança Nacional, que várias decisões-chave devem ser tomadas, tanto pelo órgão responsável pela defesa do país, como, e principalmente, pelo Presidente ou Chefe de Estado.

A primeira decisão é como o país define seus interesses nacionais, pois, para que se formule qualquer política de defesa, esta deve ter como fundamento uma clara concepção de interesse nacional, ou seja, têm que ser definidos por quais deles o país estaria disposto a, em último instância, ir à guerra. A segunda decisão é a identificação das ameaças a esses interesses. Para isso, o governo deve fazer uma análise tanto do ambiente internacional para um curto período de tempo, quanto para o de longo prazo, a fim de que se possam definir os investimentos estratégicos a serem feitos. E, por fim, se não o mais importante para as esferas seguintes, deve-se identificar os objetivos, pois são estes que irão definir as políticas e alocações de recursos de todos os setores do governo, e não somente o militar (Flournoy, 2001, 10-11).

Definidos os interesses nacionais, os objetivos e as ameaças a esses, há a necessidade de conceber uma estratégia que estabeleça as responsabilidades de cada setor do governo, ou seja, de cada ministério. Esta fase é importante porque fica definido que, dentre os diferentes objetivos nacionais a serem defendidos, quais serão aqueles de responsabilidade da área de militar, pois a articulação entre os diferentes órgãos governamentais é importante para a não sobreposição de esforços, a racionalização dos meios a serem empregados e o efetivo controle dos meios militares pelo comando civil. Além disso, só com estas definições é que se pode estabelecer as capacidades militares específicas requeridas para a execução das missões que cabem ao órgão central de defesa de um Estado (Jorndan et al, 1999, 189-197).

A Política de Defesa é, assim, a articulação entre os objetivos colocados pelo mais alto órgão político e os meios militares. Para que essa articulação possa ocorrer é necessário que se estabeleça na própria Política de Defesa, uma estratégia, pois é nela que se provê a base para todo o planejamento e a programação de prioridades para os órgãos integrantes da defesa. É importante ressaltar que é na estratégia que se deve articular claramente as escolhas sobre onde colocar ênfase, e onde e como assumir (ou administrar) os riscos, pois não há planejamento que consiga eliminar todos eles (Flournoy e Tangredi, 2001, 137-139).

A escolha da estratégia vai conduzir o processo, pois algumas definições são importantes para se prosseguir no planejamento militar. É nesse nível que se tem que responder às perguntas fundamentais, tais como, quais as prioridades estratégicas das forças armadas, o que elas devem ou não estar preparadas para fazer, a fim de defenderem os objetivos de segurança nacional, como também, 
quais as prioridades que devem ser dadas a cada tipo de missão. Porém, para se chegar a tanto, é necessário fazer outros questionamentos, tais como: que tipo de guerra as forças armadas devem estar preparadas para enfrentar nos próximos $10 \mathrm{a}$ 25 anos? Neste caso, deve-se levar em consideração o mais amplo cenário possível, pois, caso contrário, as forças estarão preparadas para somente um determinado cenário, e não para outros.

Outras questôes ainda a serem respondidas nesse nível são: em quais circunstâncias e como as forças armadas devem ser usadas em operações de não combate? Qual o papel da atualização frente às rápidas mudanças tecnológicas no campo militar? Neste caso, não significa somente a compra de novos equipamentos, mas também a modificação de conceitos operacionais, de doutrina, de educação e treinamento e de estrutura organizacional. Por fim, há de se definir os critérios para os tamanhos das forças e oferecer ao público em geral a racionalidade dessa decisão, sendo que tipicamente o critério de dimensionamento das forças delineia o número e os tipos de operações que as forças armadas deverão estar preparadas a conduzir.

O próximo nível de decisão é o de planejamento de defesa, que envolve os planos e decisões para a implementação da Política de Defesa. É neste nível que se delineia os grandes objetivos militares do país e identifica as ameaças percebidas, sendo que o planejamento de defesa tem como princípio a organização das forças militares necessárias a fim de deter essas ameaças, ou que possam lidar com elas, caso se concretizem. Esta concepção é bem resumida pelo antigo Chefe do EstadoMaior Conjunto (JCF) americano John Shalikashvili, que afirmou que a estratégia militar nacional dos Estados Unidos apontava os maiores perigos que ameaçavam os interesses norte-americanos, identificava os objetivos militares nacionais, determinava as missóes militares que deveriam ser executadas, a fim de atingir esses objetivos, e examinava as capacidades e forças necessárias (Shalikashvili, 1997, 298-310). Por isso, Neuman utiliza-se da análise de Lynn Etheridge Davis fez em relação à política nuclear americana (Davis, 1975-1976, 24-25), aplicando o mesmo procedimento ao planejamento militar convencional, dividindo-o em quatro categorias:

- Política de Emprego (Employment Policy): como um país planeja o uso do seu efetivo humano e material, a fim de evitar ou de viabilizar uma guerra. Inclui as estratégias e táticas com a intenção de lidar com as ameaças percebidas;

- Política de Aquisição (Acquisition Policy): os tipos de equipamentos militares que um país precisa comprar e os recursos para tanto;

- Política de Distribuição (Deployment Policy): onde um país aloca suas tropas e material tanto em tempos de paz como em guerra;

- Política Declaratória (Declaratory Policy): o que um governo afirma publicamente sobre seus planos e política de defesa. 
No nível mais ao centro da teia-de-aranha, aparecem a estratégia e a tática. Neuman define estratégia como a ciência e a arte de empregar todos os recursos de uma nação, ou coalizão de nações, a fim de atingir um objetivo específico da guerra. Tática é relativo aos planos e ações que têm como fim a vitória de uma específica batalha ou campanha.

Apesar da figura usada por Neuman ser muito ilustrativa para o entendimento das esferas e ordenamento das diversas etapas do planejamento da estrutura de defesa de um Estado, pode-se notar a falta de um fator muito importante, ou seja, quais são os participantes e qual seu poder de decisão em cada um desses níveis. Em nenhum momento a autora menciona qual o papel tanto dos militares quanto dos civis.

\section{As Responsabilidades de Civis e Militares}

A Democracia requer que as forças armadas, assim como os outros setores não eleitos do Executivo, sejam subordinadas aos funcionários eleitos. Paul W. Zagorski aponta muito bem que a moderna teoria democrática dá a fórmula para se estabelecer tal controle dos militares e de outros setores do Executivo, ou seja, um único chefe executivo que controla um serviço civil, o qual, por sua vez, é governado por normas legais e burocráticas (Zagorski, 1992, 51-55). Assim, ao chefe executivo cabe designar os objetivos políticos, enquanto à burocracia - tanto civil quanto militar - é suposta a execução ou administração das políticas setoriais para se alcançar tais objetivos. Esta burocracia deve ser organizada e recrutada em bases de competência técnica nos diversos campos administrativos, ou seja, este sistema pressupõe que os militares estejam sob a supervisão dos civis e a mando da Lei. Contudo, Zagorski faz a ressalva de que as forças armadas não deveriam ser excluídas das discussões das políticas públicas nas quais eles tenham pretensões justas de oferecer sua opinião técnica.

Portanto, o controle civil sobre os meios militares é essencial para a democracia. As dificuldades aparecem pelo fato de que tal controle requer conhecimento e poder. O conhecimento implica um grau suficiente de entendimento dos assuntos militares a fim de se formular políticas viáveis e críveis, englobando tanto de modo geral os assuntos militares quanto à familiaridade com suas próprias forças armadas. E poder implica na autoridade legal para se compelir e a capacidade política para se induzir à obediência, ou seja, o objetivo do controle civil é fomentar a lealdade das forças armadas ao sistema político, enquanto preserva as instituiçôes, profissionalismo e autonomia militares (Zagorski, 1992, 147-149). Contudo algumas questôes são fundamentais, e dificilmente definidas: quais as questôes que são internas às forças armadas, sobre as quais a preservação do controle militar é essencial para assegurar a autonomia, e quais as questôes que são externas e requerem uma direção política a fim de assegurar o controle civil? 
Zagorsiki ressalta que esse debate ainda está indefinido, criando o potencial para o conflito entre funcionários civis e militares. Apesar da maior parte dos que analisam estas questóes concordarem com os princípios básicos envolvendo o controle democrático das forças armadas, o debate sobre o exato significado e as implicações desses princípios são grandes. Isto se deve ao fato de que se a autoridade política for muito generalista ao estabelecer objetivos e missões para os meios militares, ela virtualmente estará abdicando das responsabilidades em favor destas, ou então, se a autoridade política for muito específica, ela estará se arriscando a entrar no micro-gerenciamanto das questões militares, além de poder, no limite, partidarizar os militares. Outro problema paralelo a este, existe com a noção de assessoramento militar e decisões das lideranças civis nas políticas da área, pois sempre haverá questionamentos de ambas as partes quando os civis não seguem o aconselhamento dos militares, e isto pode gerar a desconfiança nestes como um não reconhecimento do seu profissionalismo, ou então a desconfiança dos civis quanto ao aconselhamento militar encobrir outros posicionamentos corporativistas.

Por isso, há o debate sobre a natureza apropriada da extensão da influência militar na formulação e execução na política de defesa. A busca dessa definição já vem sendo debatida nos Estado Unidos há algum tempo como bem apontaram Jordan, Taylor e Mazarr (Jordan et al, 1999, 189-197), sendo que a corrente purista não nega a complexidade dos tópicos de segurança nacional, que são reconhecidos como uma mistura de componentes econômicos, políticos e militares, mas determinados pelos civis formuladores de políticas. Para os puristas, o militar profissional é um expert no componente militar, sendo que a experiência e o treinamento prepararam-no para fazer julgamentos sobre quais forças são necessárias para uma missão e como estas podem ser mais eficazmente utilizadas. Portanto, ao prover assessoria aos formuladores de políticas, os militares deveriam confinar-se às consideraçōes militares de uma política proposta. Ainda segundo os puristas, aos militares não se deve perguntar por assessoramento econômico ou político, pois estas áreas não são da competência deles. Entretanto, há um outro grupo com outra visão, a fusionista, que não encara a decisão militar nesses moldes.

A abordagem fusionista sustenta que, nas circunstâncias da segurança nacional de um mundo com armas nucleares, não haveria consideraçôes puramente militares, pois o setor militar consome recursos significativos, assim como o uso da força pode ter enormes implicações políticas, tanto doméstica como internacionalmente, fazendo que decisões militares tenham consequências econômicas e políticas e vice-versa. Por isso, ao dar o assessoramento, o militar profissional deveria incorporar considerações político-econômicas juntamente aos fatores militares. 
A interpretação fusionista de uma maior participação dos militares na política tem sido apontada como a solução para dois problemas. O primeiro seria que, quando os militares incorporam perspectivas políticas nas suas funçôes, isto faz que os seus assessoramentos se tornem mais influentes, realistas e relevantes para as autoridades civis que estabelecem os objetivos estratégicos do Estado, levando a um aumento do peso dos militares no processo político. A segunda vantagem seria que haveria uma diminuição no hiato entre os fins estratégicos definidos pelos civis e os meios militares disponíveis, ou mesmo instruções confusas por parte dos civis para os militares. Por esse motivo a maior parte dos líderes civis americanos tendeu a ser fusionista, assim como uma parte dos militares também o foi. Tanto é assim que os presidentes Eisenhower e, posteriormente, Kennedy instruíram tanto o estado-maior conjunto a considerar fatores político-econômicos em suas formulações militares, como os funcionários do Departamento de Estado a ouvirem as opiniōes de militares (Jordan et al, 1999, 189).

Entretanto, os críticos ao fusionismo, dentre eles Samuel Huntington, em seu trabalho The Soldier and the State, têm alertado que o aumento da visão de mundo dos militares a fim de incorporar a definição civil de "realidades políticas”, pode levá-los a atingir os níveis mais altos do processo político, mas isso não seria o adequado para uma perspectiva militar para assuntos estratégicos (Huntington, 1957, 163). Ainda segundo Huntington, o fusionismo faz a instituição militar excessivamente civil, e assim se tornar suscetível aos interesses políticos (particularmente aos domésticos) da liderança civil do governo, levando tanto militares como civis ao risco de terem responsabilidades interligadas de uma maneira confusa e debilitante. Para ele, um país e seu processo de política de segurança nacional seriam melhor servidos por militares que cultivassem seus valores organizacionais autônomos em uma instituição politicamente neutra e profissional. Ao tal profissional militar seria permitido separar-se de grande parte da sociedade que serve e estaria preocupado, primordialmente, em desenvolver e aprimorar sua perícia funcional de instrumento de guerra e de dissuasão. Assim, a análise de Huntington é mais do que uma variação da visão purista, pois para ele é essencial o isolamento cultural.

Ainda segundo alguns críticos do fusionismo, esse caráter profissional e a autonomia institucional têm feito do militar um instrumento efetivo do processo político, pois como os militares se tornam mais sensíveis às "necessidades políticas”, tanto no nível instrumental quanto no administrativo político, surge um novo padrão organizacional. O caráter burocrático do militar fica enfatizado, fazendo que os oficiais, gradualmente, redefinam seus papéis e passem a se ver como gerentes de recursos, resultando que seu papel no processo político seja dominado por suas prioridades administrativas. Além do mais, segundo os 
seus críticos, o fusionismo acelera a convergência dos valores militares e civis por todos os níveis do processo político, com o instrumento militar, tomando cada vez mais os padróes e atitudes da grande burocracia governamental. Estes críticos dizem que o estilo dominante da liderança muda do tradicional modelo "guerreiro heróico" para o mais comum "gerente técnico", com o mais alto escalão desenvolvendo um novo ethos "político-burocrático" que os envolve mais ativamente, mas menos efetivamente, no processo político. Assim, essa "convergência" entre militares e liderança civil tem impactos sérios tanto no processo de política de segurança nacional, como no instrumento militar. Edward Luttwak, um influente estrategista civil americano, criticou duramente que o propósito militar não é ser "administrativamente eficiente", pois, segundo ele, o conflito entre a eficiência civil e a eficácia militar vai de cima a baixo da organização. O combate é diferente da atividade civil, e a liderança na guerra é totalmente diferente do gerenciamento. Ele diz que o oficial americano é um gerente em uniforme. $\mathrm{Na}$ verdade, as forças armadas americanas são eficientes, elas somente não são muito efetivas (Luttwak, 1980, 38-53).

Portanto, enquanto muitos críticos do fusionismo claramente exageram os seus pontos de vista, eles conseguem efetivamente chamar a atenção para um importante dilema. A sofisticação política do militar, a sensibilidade, e seu conhecimento funcional como instrumento da política são valores complementares, contudo, eles estão sempre em tensão. Alguns críticos circunscrevem a esfera de autonomia institucional, na qual o militar pode desenvolver seu ethos profissional e conhecimento organizacional, como sendo necessário para assegurar a efetividade da função do militar como um instrumento do processo de política de segurança nacional.

Poder-se-ia, para uma melhor compreensão da participação de civis e militares, elaborar um gráfico no qual ficaria mais clara essas responsabilidades, como pode ser observado na figura número dois abaixo.

No gráfico pode-se observar com mais clareza a proposta de Zagorski, segundo a qual a Grande Estratégia (como chamam os ingleses, ou Estratégia Nacional para os americanos), ou seja, a coordenação feita no nível mais elevado da Política para o emprego dos meios militares, políticos ou econômicos, em relação a interesses nacionais, inimigos e ameaças, deveria ser formulada por civis com assessoramento militar. Portanto, as concepções de Grande Estratégia resultantes desse processo deverão ser críveis para os militares, a fim de que não haja discordâncias profundas. O resultado seria a definição de uma Estratégia, que por sua vez resulta em uma Política Militar, que é a designação do número de homens, material bélico e outros recursos militares, além dos princípios gerais de organização do sistema militar, e este também deve ser feito sob controle civil com assessoramento militar (ou segundo Neuman, as políticas de emprego, aquisição, distribuição e declaratória). 
Figura $2^{5}$

Participação civil e militar

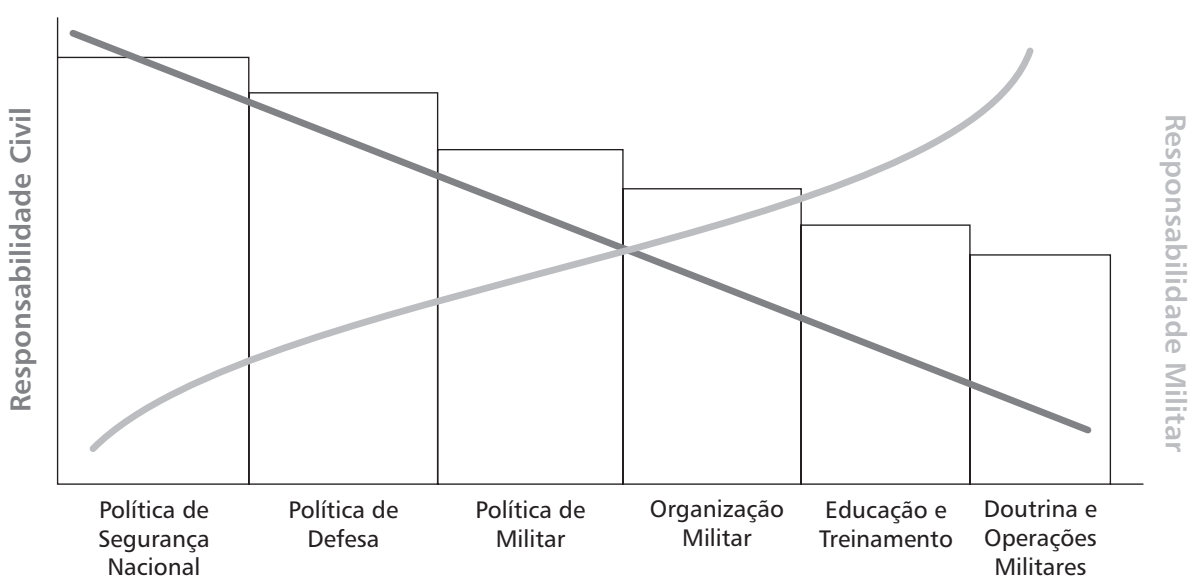

Para Zagorski a Estratégia Operacional (Estratégia Militar na figura), ou seja, a maneira pela qual as guerras devem ser combatidas deverá ser desenvolvida pelas forças armadas sob a direção e aprovação das autoridades civis. Já a Tática, ou seja, como as forças são organizadas e empregadas a fim de se ganhar as batalhas, deverá estar quase totalmente sob direção militar (Zagorski, 1992, 147-149). ${ }^{6}$ Vale a pena a ressalva que Zagorski faz de como esses componentes tem de integrar-se de forma total coerentemente. Todo esse processo, bem representado pelas figuras 1 e 2, evidencia quais as áreas abrangidas por cada nível político e a participação de civis e militares em cada fase.

\section{Conclusão}

$\mathrm{Na}$ literatura internacional sobre segurança, não se conseguiu chegar a um consenso sobre uma definição aceita tanto pela corrente tradicional como pela nova. Entretanto, a visão de que segurança é sinônimo da proteção contra ameaças externas aos interesses vitais e aos valores básicos de um Estado é a mais aceita. Dentro deste debate, a crítica de Mohammed Ayoob sobre esta concepção, que ele chama "Conceito Ocidental de Segurança" é irrefutável, pois, para ele, ao se

5 Gráfico adaptado a partir da apresentação da palestra "Desafios para a Gestão dos Recursos de Defesa em Sociedades Democráticas", da Dra. Margaret Daly Hayes, na época Diretora do Center for Hemisferic Defense Studies, durante o Seminário sobre Economia e Gestão de Recursos de Defesa, em Brasília, ocorrido de 6 a 10 de maio de 2002, oferecido pelo Ministério da Defesa e CHDS.

6 Segundo o autor, essa divisão de atividades é baseada em CLAUSEWITZ, Karl von, On War, editado e traduzido por Howard, Michael, Paret, Peter. Baltimore: Penguin Books, 1968, p. 119 e p. 173. 
procurar visualizar as ameaças e vulnerabilidades, tanto internas quanto externas de cada Estado, se poderá ter melhor explicação para cada caso que se analise. Isto se dá porque, para ele, o foco da análise de segurança tem que partir do princípio de cada Estado está em uma fase diferente do processo de State Building. Assim, os baixos níveis de coesão social, legitimidade tanto do Estado quanto do seu regime, são as principais causas da insegurança interna dos países menos desenvolvidos.

Portanto, o conceito de segurança deve ser entendido como sendo explicitamente no sentido político. Ele deve ser aplicado à segurança do Estado, em termos de território, suas instituições e daqueles que o representam. Ou seja, uma situação de segurança/insegurança é definida em relação às vulnerabilidades, tanto internas quanto externas, que ameacem ou tenham o potencial de derrubar ou enfraquecer as estruturas do Estado (territorial e institucional) e seu regime político. O passo seguinte é como conseguir definir qual assunto pode ser considerado dentro deste conceito.

Como defendido por Buzan, Waver e Wilde, qualquer assunto público pode ser posicionado no espectro que varia do não-politizado, passando por politizado, até securitizado. Somente se pode falar em segurança nacional quando um assunto é apresentado como sendo uma ameaça real ao Estado, este incorporando o governo, território e sociedade. A securitização se dá quando se invoca a segurança nacional, o que possibilita levar a política além das regras do jogo estabelecidas e enquadra o assunto tanto como um tipo especial, justificando o uso de medidas extraordinárias, a fim de lidar com ela e legitimando o processo. Portanto, um tópico torna-se de segurança não necessariamente por causa da existência de uma ameaça real, mas porque ele é apresentado como uma ameaça.

Partindo desse princípio e adotando o modelo de Stephanie Neuman, pode-se diminuir a confusão sobre os conceitos de Segurança Nacional, Defesa Nacional e Estratégia de Defesa, pois é possível visualizar de forma conjunta e de uma maneira muito apropriada a hierarquia das esferas políticas.

No nível mais alto de decisão política está a Política de Segurança Nacional. É nesta esfera que são articulados tanto os interesses nacionais mais amplos, e a estratégia para articular quanto os objetivos do país e os seus meios (militares, econômicos, sociais e políticos) que serão usados a fim de promover e protegê-los. Estes instrumentos são organizados na esfera seguinte, nas diferentes políticas setoriais, como saúde, monetária, comércio exterior, agricultura, imigração, educação, defesa dentre outras.

Neste ponto que fica claro o escopo e a hierarquização das Políticas de Segurança Nacional e de Defesa Nacional. Tomando por base que o processo de securitização só pode ser feito no nível mais alto da tomada de decisão política, por conseguinte, a implementação de políticas setoriais só pode ser feita em um nível inferior, que, no caso de utilização dos meios militares, é a Política de Defesa. 
Como visto, a securitização se dá de acordo com a realidade de cada Estado. É no nível mais alto da política que se vai definir quais os temas que devem ser securitizados de acordo com as suas percepçôes de ameaças ou vulnerabilidades, sejam eles internos ou externos. Assim, cada governo explicita quais os assuntos que serão abordados pelos seus respectivos órgãos, mas que não necessariamente serão resolvidos com o emprego do uso dos meios militares. Se houver vulnerabilidades econômicas, por exemplo, o ministério responsável por esta esfera de política é que será responsável pelas açôes, como seria o caso do ministério da saúde em casos da sua pasta. Se a securitização for feita em relação a assuntos que devam ser solucionados via uso da força militar, esse será o referencial para a política setorial específica, ou seja, a Política de Defesa.

É com base nesse processo que, na Política de Defesa, estabelecem-se parâmetros imprescindíveis para a área militar. É nesta política que se define a estratégia a ser seguida, já que esta estabelece o planejamento e a programação de prioridades para os órgãos integrantes da defesa e da formulação do planejamento de defesa. Como visto, é neste nível que se fixa vários pontos importantes para a estruturação das forças armadas de um país, como prioridades, missóes, emprego, atualizações, oferecendo ao público em geral a racionalidade dessa decisão.

O próximo nível de decisão é o de Planejamento de Defesa, no qual devem ser definidas a Política de Emprego, a Política de Aquisição, a Política de Distribuição e a Política Declaratória. Por último, ficam a Estratégia Operacional e a Tática, ligados diretamente ao emprego da força.

A definição do que fazer em cada nível só pode ser completa se também estiver determinado quem participa desse processo, mais conhecido como o debate do relacionamento civil-militar. Esse debate também não tem consenso, principalmente no que se refere ao papel dos militares, tendo as correntes purista $\mathrm{e}$ fusionista defendido lados opostos. Os puristas com a concepção de que os militares devem se concentrar somente nos aspectos ligados ao emprego da força, enquanto os fusionistas com a ideia de que os militares são parte do corpo governamental que têm que participar de todo o processo político.

A figura elaborada pela Dra. Margareth Hayes facilita essa compreensão. Partindo do nível mais alto da Política de Segurança Nacional até ao emprego da força em campo, os dois lados participam, só que em proporçõos diferenciadas. Quanto mais alto o nível político, maior participação civil e menor o militar, chegando a inverter quando chega no nível tático.

Apesar de não haver consenso tanto para o conceito de segurança quanto para os níveis das políticas governamentais dessa área, e muito menos para o papel dos militares neste processo, esta estrutura teórica contribui para o ordenamento desse debate, principalmente no Brasil, onde este assunto ainda é relativamente recente. 


\section{Referências bibliográficas}

ALSINA JR, João Paulo Soares. A síntese imperfeita: articulação entre política externa e política de defesa na era Cardoso. Revista Brasileira de Política Internacional, Vol. 46, No 2, 2003, p. $53-86$.

Аүоов, Mohammed. The Security Predicament of the Third World State: Reflections on State-Making in a Comparative Perspective In: JoB, Brian (Ed.). The Insecurity Dilemma: National Security of Third World States. Boulder, C.O.: Lynne Rienner Publishers, 1992, p. 63-80.

. Security in the Third World: Searching for the Core Variable. In: Graham, Norman (Ed.). Seeking Securityt and Development: The Impact of Military Spending and Arms Transfers. Boulder: Lynne Rienner Publishers, 1994.

Inc., 1995.

The Third World Security Predicament. Boulder, C.O.: Lynne Reinner Publishers,

Azar, Edward E. e Moon, Chung-in (1998). Legitimacy, Integration and Policy Capacity: The 'Software' Side of Third World National Security. In: AzAR, Edward E. e Moon, Chung-in (Eds.) National Security in the Third World: The Management of Internal and External Threats. College Park: Center for International Development and Conflict Management, University of Maryland, 1998, p. 77-101.

Brodie, Bernard. War and Politics. London: Cassell, 1973.

Bull, Hedley. The Control of the Arms Race. London: Weindenfeld e Nicolson, 1961.

Buzan, Barry, Waever, Ole e Wilde, Jaap de. Security. A New Framework for Analysis. Boulder, C.O.: Lynne Reinner Publishers, 1998.

COSTA, Darc. Segurança e Defesa: uma única visão abaixo do Equador. Revista Brasileira de política Internacional, Vol. 42, No 1, 1999, p. 127- 156.

Davis, Lynn Etheridge. Limited Nuclear Options: Deterrence and the New American Doctrine. Adelphi Papers, no. 121 (Winter 1975-1976): n.1, p. 24-45.

Flores, Mario Cesar. Reflexões Estratégicas. Repensando a defesa nacional. São Paulo: É Realizações, 2002.

Flournoy, Michèle A. Introduction: Twelve Strategy Decisions. In: Flournor, Michèle A. (Ed.). QDR 2001. Strategy-Driven Choices for America's Security. Washington, DC: National Defense University Press, 2001, p. 3-24.

Flournoy, Michèle A. e Tangredi, Sam J.. Defense Strategy Alternatives: Choosing Where to Place Emphasis and Where to Accept Risk. In: Flournoy, Michèle A. (Ed.). QDR 2001. Strategy-Driven Choices for America's Security. Washington, DC: National Defense University Press, 2001, p. 137-166.

Goldman, Kjell. Det Internationella Systemet. Stockholm: Aldus, 1978, p. 64, apud Sundelius, Bengt. Coping with structural security threats. In: HöLL, Otmar (Ed.), Small States in Europe and Dependence. Vienna: Austrian Institute for International Affairs, 1983, p. 298.

Gray, Coli S. Villains, Victims and Sheriffs: Strategic Studies and Security for an Inter-War Period. Hill: University of Hull Press, 1994.

Haftendorn, Helga. The Security Puzzle: Theory-Building and Discipline-Building in International Relations. International Studies Quarterly, 35:1 (1990) pp. 3-17. 
Herz, John H. International Politics in the Atomic Age. New York: Columbia University Press, 1959.

Howard, Michael, Paret, Peter. Baltimore: Penguin Books, 1968.

Huntington, Samuel P. The Soldier and the State. Cambridge, Mass.: Harvard University Press, 1957.

Jaggers, Keith. War and the Three Faces of Power: War Making and State Making in Europe and the Americas, Comparative Political Studies 25, no.1 (April 1992), p. 29.

Jahn, Egbert, Lemaitre, Pierre e Waever, Ole. Concepts of Security: Problems of Research on Non-Military Aspects. Copenhagen Papers, no.1. Copenhagen: Center for Peace and Conflict Research, 1987.

Jervis, Robert. Perception and Misperception in International Politics. Princeton, NJ: Princeton University Press, 1976.

Jordan, Amos A., Taylor, William J., Mazarr, Michael J.. American National Security. Baltimore: Johns Hopkins University Press, 1999.

Lebow, Richard N. Interdisciplinary Research and the Future of Peace and Security Studies. Political Psychology, 9:3 (1988) pp. 507-543, 508.

LUTTWAK, Edward N. A Critical View of the U.S. Military Establishment. Forbes, May 26, 1980 , p. 38-53.

Mathews, Jessica Tuchman. The Environment and International Security. In: Klare, Michael e Thomas, Daniel (Eds.). World Security: Trends and Challenges at Century's End. New York: St. Martin's Press, 1991, p. 362-380.

Mathews, Jessica Tuchman. Redefining Security. Foreign Affairs, 68:2, 1989, p. 162-77.

Neuman, Stephanie G. Defense Planning in Less-Industrialized States. Lexington, Massachusetts, Toronto: Lexington Books, 1984.

Nye, Joseph S. The Contribution of Strategic Studies: Future Challenges. Adelphi Paper no 235. London: International Institute for Strategic Studies, 1989.

NyE, Joseph S., e Lynn-Jones, Sean M. International Security Studies. International Security, $12: 4,1988$, p. 5-27.

Proença Jr., Domício e DINIZ, Eugênio. Política de Defesa no Brasil: uma análise crítica. Brasília: Editora Universidade de Brasília, 1998.

Shalikashvili, John M. The National Military Strategy of the United States of America. In: Hays, Peter L., Vallance, Brenda J., e Tassel, Alan R. Van. American Defense Policy. Baltimore: Johns Hopkins University Press, 1997, p. 298-310.

Thomas, Caroline. In Search of Security: The Third World in International Relations. Boulder, C.O.: Lynne Rienner Publishers, 1987.

Tilly, Charles. War Making and State Making as Organized Crime. In: Evans, Peter B., Rueschemeyer, Dietrich e Skocpol, Theada (Eds.). Bringing the State Back In. New York: Cambridge University Press, 1985.

TREVISAN, Leonardo N. As Obsessões Patrióticas: origens e projetos de duas escolas de pensamento político do Exército brasileiro. Tese de doutorado apresentada ao Departamento de Ciência Política da FFLCH da USP, São Paulo, 1993. 
Waever, Ole. Securitization and Desecuritization, In: Lipschutz, Ronnie D. (Ed.). On Security. New York: Columbia University Press, 1995, p. 46-86.

ZAGORSKI, Paul W. Democracy vs. National Security. Civil-Military Relations in Latin America. Boulder, C.O.: Lynne Rienner Publishers, 1992.

Recebido em 13 de março de 2009 Aprovado em 20 de agosto de 2009

\section{Resumo}

No artigo se busca uma delimitação de conceitos e abrangência dos níveis de cada política da área de defesa e participação de civis e militares.

\section{Abstract}

The aim of the paper is to delimit the definition of both concepts and levels of coverage of each policy in the Defense area and civil and military participation.

Palavras-chave: Segurança Internacional; Segurança Nacional; Defesa.

Key-words: International Security; National Security; Defense. 